\title{
The effect of different treatments for early-lactation hyperketonemia on blood $\beta$-hydroxybutyrate, plasma nonesterified fatty acids, glucose, insulin, and glucagon in dairy cattle
}

\author{
S. Mann, ${ }^{* 1}$ F. A. Leal Yepes, † E. Behling-Kelly, ${ }^{*}$ and J. A. A. McArt ${ }^{*}$ \\ *Department of Population Medicine and Diagnostic Sciences, and \\ †Department of Animal Science, Cornell University, Ithaca, NY 14853
}

\begin{abstract}
Despite increased efforts in preventing the occurrence of metabolic disorders in transition cows, hyperketonemia remains a frequent early-lactation metabolic disease affecting an average of $40 \%$ of cows in herds in the United States. Despite the demonstrated economic effect of this disorder, controlled clinical trials comparing different treatment strategies in affected cows are lacking. The objective of our study was to investigate the effect of treatment with intravenous glucose, oral propylene glycol, or a combination of both on the reduction in blood $\beta$-hydroxybutyrate (BHB) concentrations of early-lactation hyperketonemic dairy cows. Multiparous Holstein cows between 3 to $9 \mathrm{~d}$ in milk were screened for hyperketonemia using a handheld meter 3 times per week, and enrolled at whole blood BHB concentration $\geq 1.2 \mathrm{mmol} / \mathrm{L}$ to 1 of 4 treatment groups: (1) $500 \mathrm{~mL}$ of a $50 \%$ dextrose solution i.v. once daily for $3 \mathrm{~d}$ (GLU, n $=9)$, (2) $300 \mathrm{~mL}$ of propylene glycol as a drench once daily for $3 \mathrm{~d}(\mathrm{PG}, \mathrm{n}=9)$, (3) a combination treatment of a $500 \mathrm{~mL}$ of $50 \%$ dextrose solution i.v. and $300 \mathrm{~mL}$ of propylene glycol orally once daily for $3 \mathrm{~d}$ (GLU+PG, $\mathrm{n}=8$ ), or (4) an untreated control group (CTRL, $\mathrm{n}=$ $8)$. Blood samples were collected immediately before as well as at 1, 2, 4, 8, 12, 24, 36, 48, 60, and $72 \mathrm{~h}$ after administration of the first treatment through a jugular catheter and 3 times per week thereafter from coccygeal vessels. Concentrations of BHB were measured in whole blood, and plasma samples were analyzed for glucose, fatty acid (NEFA), insulin, glucagon, and electrolyte concentrations. The EDTA-anticoagulated blood samples were assessed for red blood cell indices, and smears were made for evaluation of red blood cell morphology. Outcomes were analyzed using repeated measures analysis. Overall least squares means (95\% $\mathrm{CI}$ ) of whole blood BHB concentrations between $1 \mathrm{~h}$
\end{abstract}

Received December 29, 2016.

Accepted April 2, 2017.

${ }^{1}$ Corresponding author: sm682@cornell.edu and $\mathrm{d} 11$ relative to first treatment were 1.11 (0.95 to 1.30 ), 1.26 (1.07 to 1.47 ), 0.96 (0.81 to 1.13 ), and 1.53 (1.30 to 1.80$) \mathrm{mmol} / \mathrm{L}$ for the GLU, PG, GLU+PG, and CTRL groups, respectively. Treatment with both glucose and propylene glycol led to a greater magnitude and more prolonged decrease in BHB concentrations compared with individual treatments. The NEFA and glucagon concentrations were lower immediately after treatment in GLU and GLU+PG groups compared with CTRL, and treatment with both glucose and propylene glycol was associated with a greater increase in glucose and insulin concentrations immediately after treatment compared with CTRL and GLU treatment alone. Treatments did not lead to differences in plasma mineral concentrations. We conclude that treatments varied in the magnitude of decreasing blood BHB concentrations in hyperketonemic postpartum cows, with the greatest decline after treatment with a combination of intravenous glucose and oral propylene glycol.

Key words: ketosis, treatment, glucose, propylene glycol, insulin

\section{INTRODUCTION}

During the last decade, a considerable amount of work has been completed linking postpartum hyperketonemia to negative health outcomes, such as displacement of the abomasum, metritis, as well as an increased risk of herd removal and a loss in reproductive success and milk production (Duffield et al., 2009; Ospina et al., 2010; Roberts et al., 2012). Despite an increase in scientific knowledge about risk factors for early-lactation hyperketonemia (McArt et al., 2013; Tao and Dahl, 2013; Berge and Vertenten, 2014) and nutritional strategies aimed at preventing this metabolic disorder (Lean et al., 2013; Roche et al., 2013; Mann et al., 2015), an average of $40 \%$ of postpartum cows experience at least one hyperketonemic event during early lactation (McArt et al., 2012b), which we recently estimated to have an economic effect of $\$ 289$ per case (McArt et al., 2015). A variety of treatment strategies for hyperke- 
tonemia are used and commonly include administration of intravenous dextrose, as well as oral medication with glucogenic precursor substances such as propylene glycol. We showed that oral drenching with propylene glycol not only helped resolve hyperketonemia but also reduced the risk for displacement of the abomasum, decreased early-lactation culling risk, and increased milk production (McArt et al., 2011, 2012a).

Despite widespread use, information from controlled clinical studies is lacking on the effect of intravenous glucose in the treatment of early-lactation hyperketonemia (Gordon et al., 2013). Wagner and Schimek (2010) showed that postpartum cows treated with 500 or $1,000 \mathrm{~mL}$ of $50 \%$ intravenous dextrose solution as a single bolus were at risk for hypophosphatemia, a condition that is associated with downer cow syndrome and postparturient hemoglobinuria (Grünberg, 2014). The usefulness of the few available controlled studies on possible detrimental effects of intravenous administration of a glucose bolus has partially been hampered by the fact that treatments were applied to nonlactating (Holtenius et al., 2000) or to fresh cows with or without hyperketonemia (Wagner and Schimek, 2010), which may differ drastically in hormonal milieu and energy balance, and thus response in reduction of BHB concentrations from the animals receiving these treatments on dairy farms.

Although the described treatments are among those most commonly recommended for treatment of hyperketonemia in postpartum dairy cattle, evidence for their use and a comparison of their respective metabolic consequences alone or in combination are largely unstudied, especially in randomized controlled studies. Important metabolic consequences include the effect of treatments on the concentrations of markers of negative energy balance, and hormonal control of metabolism through insulin and glucagon signaling because both pancreatic hormones play a role in early-lactation ketogenesis (Brockman, 1979). In addition, we wanted to describe possible effects on blood electrolyte balance and red blood cell toxicity because toxic side effects have been reported for propylene glycol and can occur at doses as low as $40 \mathrm{~g}$ (Nielsen and Ingvartsen, 2004). Although evidence from other species indicates this might be the case (Potter, 1958; Bauer et al., 1992), a possible effect of propylene glycol treatment on red blood cells has not been evaluated in hyperketonemic postpartum dairy cattle to the best or our knowledge.

Thus, our aim was to address the gap in knowledge regarding the effects of commonly used treatments alone or in combination in the appropriate study population, cows with naturally occurring hyperketonemia in the immediate postpartum period. Our hypothesis was that different treatment strategies commonly used for early postpartum hyperketonemia differ in their ability to reduce the concentrations of BHB and would differ in their effect on concentrations of plasma fatty acids (NEFA), glucagon, insulin, glucose, as well as plasma electrolytes. In addition we investigated possible effects of treatments on red blood cell morphology.

\section{MATERIALS AND METHODS}

All procedures were evaluated and approved by the Cornell University Institutional Animal Care and Use Committee (protocol no. 2015-0097). Multiparous Holstein cows between 3 and 9 DIM at the Cornell University Ruminant Center in Harford, New York, were screened for blood BHB concentrations between January and July 2016. After the morning milking at $0700 \mathrm{~h}$, fresh cows were locked up 3 times per week and whole blood BHB concentration was measured by taking a 1-mL blood sample from the coccygeal vessels using a syringe and needle and immediately applying the sample to a handheld meter (TaiDoc, Pharmadoc, Lüdersdorf, Germany) recently validated for use with bovine blood samples (Bach et al., 2016). Cows were enrolled in 1 of 4 treatment groups following a randomized block design when whole blood BHB concentration was $\geq 1.2 \mathrm{mmol} / \mathrm{L}$.

\section{Samples and Treatments}

At enrollment, cows were weighed and moved to a treatment area where an extended use 14 gauge $\times 13.3$ $\mathrm{cm}$ jugular catheter (Milacath, Mila International, Florence, KY) was placed in 1 jugular vein after administration of 0.003 to $0.005 \mathrm{mg} / \mathrm{kg}$ of acepromazine maleate (VetOne, Boise, ID) i.v. as described previously (Mann et al., 2016). Blood samples were obtained through an intravenous extension set connected to the catheter immediately before the first treatment $(0 \mathrm{~h})$, as well as at $1,2,4,8,12,24,36,48,60$, and $72 \mathrm{~h}$ relative to treatment, after which the jugular catheter was removed. From the day after removal of the catheter until the end of the study period at 21 DIM, blood samples (10 $\mathrm{mL}$ ) were taken 3 times a week before feeding (between 0600 and $0700 \mathrm{~h}$ ) from the coccygeal vessels.

Cows were allocated to 1 of 4 groups using a randomized block design: (1) $500 \mathrm{~mL}$ of a $50 \%$ dextrose solution (dextrose $50 \%$ injection, VetOne) i.v. once a day for $3 \mathrm{~d}$ (GLU, n = 9), (2) $300 \mathrm{~mL}$ of propylene glycol (100\% propylene glycol, USP, VetOne) orally once a day for $3 \mathrm{~d}$ (PG, $\mathrm{n}=9$ ), (3) $500 \mathrm{~mL}$ of a $50 \%$ dextrose solution i.v. and $300 \mathrm{~mL}$ of propylene glycol orally once a day for $3 \mathrm{~d}(\mathbf{G L U}+\mathbf{P G}, \mathrm{n}=8)$, or (4) an untreated control group $(\mathbf{C T R L}, \mathrm{n}=8$ ). Propylene glycol was administered as a drench immediately 
before morning feeding using a manual drenching gun (Neogen, Lexington, KY). Glucose was administered as a rapid infusion after warming to body temperature through the jugular catheter. Samples at 24 and $48 \mathrm{~h}$ were taken immediately before administration of the second and third treatment, respectively. Animals in the GLU+PG group received intravenous glucose first, followed immediately by oral propylene glycol after the infusion was completed. To ensure patency, catheters and intravenous extension lines were filled with a $20 \mathrm{IU} /$ $\mathrm{mL}$ of $0.9 \%$ heparinized sterile saline solution between sampling time points. All blood samples were collected into evacuated tubes (Becton Dickinson Vacutainer Systems, Franklin Lakes, NJ) with 158 USP units of sodium heparin for plasma separation with a 20 gauge $\times 2.54 \mathrm{~cm}$ blood collection needle. In addition, at 0 and $72 \mathrm{~h}$ posttreatment, whole blood samples were collected in evacuated tubes with $0.10 \mathrm{~mL}$ of a $15 \%$ EDTA solution (Covidien Monoject, Medtronic, Minneapolis, $\mathrm{MN})$. All blood samples were immediately placed on ice, and heparinized plasma was obtained within 60 min of sampling by centrifugation at $2,800 \times g$ for 20 min at $4^{\circ} \mathrm{C}$. Plasma samples were stored in aliquots at $-20^{\circ} \mathrm{C}$ until the end of the study period when samples were moved to a $-80^{\circ} \mathrm{C}$ freezer for long-term storage.

Liver biopsies were obtained from all cows at 0 and $72 \mathrm{~h}$ (data not shown) and cows received $1.1 \mathrm{mg} / \mathrm{kg}$ flunixine meglumine (Prevail, VetOne) i.v. for minor pain relief on both days immediately following the procedure.

\section{Diets and Management}

At enrollment, cows were moved to individual sawdust-bedded tie-stalls with feed bins until the end of the study period. The same fresh cow TMR was offered to cows eligible for enrollment and those enrolled in the study. Diet formulation and analyzed composition is summarized in Table 1. Dry matter content of all feed components including the grain mix and TMR was determined on a weekly basis by drying the sample at $60^{\circ} \mathrm{C}$ for $48 \mathrm{~h}$. Rations were adjusted each week for changes in DM content of the component. Weekly TMR samples were sent for near infrared reflectance analysis to a commercial laboratory (Cumberland Valley, Maugansville, MD). The TMR was offered ad libitum, fed once daily at $0900 \mathrm{~h}$ and amounts fed were adjusted to allow for a minimum of $5 \%$ refusals. Individual feed intakes were recorded daily and calculated on a DM basis using the weekly information as described above. All cows were milked 3 times a day throughout the study and milk weights for every milking were recorded. In addition to measuring BHB concentrations in whole blood, cows were evaluated for signs of clinical ketosis
Table 1. Analyzed composition (mean $\pm \mathrm{SD}$ ) of $\operatorname{diets}^{1}$

\begin{tabular}{lcc}
\hline Item & Dry & Fresh \\
\hline $\mathrm{DM}(\%)$ & $49.2 \pm 4.6$ & $51.99 \pm 2.9$ \\
$\mathrm{NE}(\mathrm{Mcal} / \mathrm{kg}$ of DM) & $1.48 \pm 0.05$ & $1.63 \pm 0.03$ \\
$\mathrm{CP}(\%$ of DM) & $13.7 \pm 0.9$ & $15.5 \pm 0.8$ \\
$\mathrm{ADF}(\%$ of DM) & $28.2 \pm 2.3$ & $21.6 \pm 1.6$ \\
aNDF ${ }^{2}(\%$ of DM) & $42.2 \pm 3.3$ & $31.7 \pm 2.1$ \\
Starch $(\%$ of DM) & $19.5 \pm 3.1$ & $25.7 \pm 2.7$ \\
Ether extract $(\%$ of DM) & $3.1 \pm 0.3$ & $3.4 \pm 0.2$ \\
Ash (\% of DM) & $8.2 \pm 0.7$ & $7.9 \pm 0.5$ \\
Ca (\% of DM) & $1.54 \pm 0.35$ & $0.89 \pm 0.09$ \\
$\mathrm{P}(\%$ of DM) & $0.31 \pm 0.04$ & $0.36 \pm 0.03$ \\
$\mathrm{Mg}(\%$ of DM) & $0.52 \pm 0.07$ & $0.46 \pm 0.05$ \\
$\mathrm{~K}(\%$ of DM) & $1.20 \pm 0.16$ & $1.28 \pm 0.41$ \\
$\mathrm{~S}(\%$ of DM) & $0.42 \pm 0.05$ & $0.37 \pm 0.03$ \\
$\mathrm{Na}(\%$ of DM) & $0.13 \pm 0.02$ & $0.77 \pm 0.11$ \\
$\mathrm{Cl}(\%$ of DM) & $0.64 \pm 0.07$ & $0.51 \pm 0.05$ \\
$\mathrm{DCAD}(\mathrm{mEq} / 100 \mathrm{~g}$ of DM) & $-7.8 \pm 5.5$ & $31.7 \pm 6.1$ \\
\hline
\end{tabular}

${ }^{1}$ Near-infrared spectroscopy of 22 dry-period and fresh-period TMR composite samples, respectively (Cumberland Valley, Maugansville, MD).

${ }^{2} \mathrm{NDF}$ determination with amylase and sodium sulfite.

(lethargy, depression, abnormal behavior, central nervous symptoms) at least twice daily during treatments and daily thereafter until leaving the study at 21 DIM. All health events were recorded by the same veterinarian overseeing treatments.

\section{Laboratory Analysis}

The concentration of BHB was determined for every blood sample cow-side using a recently validated handheld device as described above. Plasma glucose (PGO enzyme preparation, Sigma Aldrich, St. Louis, MO) and NEFA [HR Series NEFA-HR (2), Wako Life Sciences, Mountain View, CA] concentrations were measured by colorimetric assay in duplicate from all samples. For quality control, in-house bovine plasma quality control samples were run on every plate. Intra- and interassay coefficients of variation were 2.2 and $1.8 \%$ for glucose and 2.2 and $5.5 \%$ for NEFA, respectively. Radioimmunoassays were used to measure plasma insulin (Insulin RIA kit, RI-13 K, EMD Millipore, St. Charles, MO) and glucagon (Glucagon RIA kit, GL-32 K, EMD Millipore) for duplicate samples in the Endocrinology Laboratory of the New York State Animal Health Diagnostic Center (AHDC). Intra- and interassay coefficient of variation of control samples were 5.0 and $6.9 \%$ for the insulin assay, and 7.6 and $5.4 \%$ for the glucagon assay, respectively. Molar insulin:glucagon ration was determined as previously described (Mann et al., 2016). Plasma samples of all cows from $0,1,2,4,8,12,24$, $36,48,60$, and $72 \mathrm{~h}$ time points were submitted to the AHDC for analysis of plasma electrolytes (Roche P Modular Chemistry Analyzer). Phosphate concen- 
trations in plasma are those of orthophosphate. Blood smears were produced within $1 \mathrm{~h}$ of collection from EDTA blood taken at 0 and $72 \mathrm{~h}$, stained with WrightGiemsa using an automated stainer (Hematek, Siemens, Erlangen, Germany) and stored for later evaluation of all smears for evaluation of red blood cell morphology and determination of the differential white blood cell counts by a board-certified clinical pathologist who was blinded to treatments. The EDTA whole blood samples were submitted on the day of sampling to the AHDC for automated hemogram (Advia 2120, Siemens).

\section{Analytical Approach}

Our primary outcome of interest was the difference in BHB blood concentrations after initiation of treatment. The sample size of 8 animals per group was based on identifying a difference in BHB reduction for our anticipated response of a hyperketonemic cow enrolled, on average, on d 5 postpartum of at least $0.4 \mathrm{mmol} / \mathrm{L}$ in the single treatment groups, and $0.8 \mathrm{mmol} / \mathrm{L}$ in the combination treatment group compared with the control group, applying a power of $95 \%$ and a significance level of 0.05 , and a SD of BHB concentration of 0.4 $\mathrm{mmol} / \mathrm{L}$. Allocation to treatments within blocks of 4 cows was performed following the sequence obtained from a random number generator (Research Randomizer v.4.0, Urbaniak and Plous, 2012). One animal each was added to the PG and GLU group because liver biopsy was unsuccessful at one time point for one cow in each of the 2 groups, resulting in 9 animals in these 2 groups as complete information on all animals was required for a separate objective of this study. Secondary outcomes included differences in NEFA, glucose, insulin, glucagon, blood mineral balance, and hematology findings. In addition, information on DMI and milk production was collected.

Differences in weight, BHB concentration at enrollment, as well as DIM at enrollment were analyzed using mixed effects ANOVA with treatment group as fixed and block as random effect, pairwise comparisons across groups were adjusting for multiple comparisons using Tukey's posthoc test. Differences in parity groups and BCS at enrollment were investigated using Fisher's exact test. The maximal change from baseline in the first $24 \mathrm{~h}$ of treatment was calculated as the difference between concentration at baseline and the concentration at the time point of maximal decrease of BHB, NEFA, and glucagon concentrations, or the maximal increase of glucose and insulin concentrations, respectively. Differences in maximal response were analyzed using mixed effects ANOVA with the fixed effects of group and DIM at enrollment, as well as the random effect of block. Multiple comparisons across groups in the case of significant $F$-tests were controlled by applying Tukey's posthoc test.

For outcomes with repeated measurements over time, repeated measures ANOVA was performed (BHB, NEFA, glucose, insulin, glucagon, plasma minerals, hemogram, DMI, milk production). Because measurements were unevenly distributed over time, the covariance structures tested included unstructured, spatial power law, Gaussian, and spherical. Fixed effects were treatment group, time, and their interaction. For repeated measures with only 2 outcomes (hematology), no baseline covariate was used. For outcomes with more than 2 measurements, covariates included in the model were concentration of the parameter at baseline $(0 \mathrm{~h}$, except for DMI where this information was not available) and DIM at enrollment, such that time points included in the dependent variable ranged from 1 to $72 \mathrm{~h}$ for plasma electrolytes, from $1 \mathrm{~h}$ to the third weekly sample for energy metabolites and pancreatic hormones, and from the treatment period to $15 \mathrm{~d}$ or wk 4 postenrollment for DM and milk yield, respectively. The REPEATED statement was specified for the time variable. Enrollment block was included as a random effect in all models and normality of residuals was tested after each model fit. To achieve normality of residuals, the dependent variables insulin, glucagon, the insulin:glucagon molar ratio, BHB, NEFA, glucose, eosinophil, and monocyte counts were log-transformed. For comparison of groups across a single time point, $P$-values were adjusted for multiple comparisons with Tukey's post-hoc test to control experiment-wise error rate; those with repeated measures were controlled for multiple comparisons with Sidak's adjustments for the number of time points considered in the analysis. Outliers were evaluated using Cook's distance for repeated measures ANOVA and defined as having values $>0.5$. All statistical analyses were performed in SAS (v. 9.4, SAS Institute Inc., Cary, NC). Graphs were produced in GraphPad Prism (v. 7.01, La Jolla, CA). Results are presented as least squares means or geometric least squares means, and 95\% confidence interval unless otherwise specified.

\section{RESULTS}

\section{Description of Study Population}

A total of $10(29.4 \%), 12(35.3 \%), 8(23.5 \%)$, and 4 $(11.8 \%)$ cows were in second, third, fourth, and fifth lactation and parity distribution was not different between groups $(P=0.54)$. The average DIM at enrollment was 5.1 (4.0 to 6.2 ), 5.7 (4.6 to 6.7 ), 4.8 (3.6 to 5.9 ), and 5.6 (4.5 to 6.7$)$, respectively $(P=0.58)$. Body weight at enrollment was 729 (678 to 780 ), 701 (650 to 
Table 2. Least squares means $(95 \% \mathrm{CI})$ of maximal response of selected analytes at any time point in the first $24 \mathrm{~h}$ after treatment

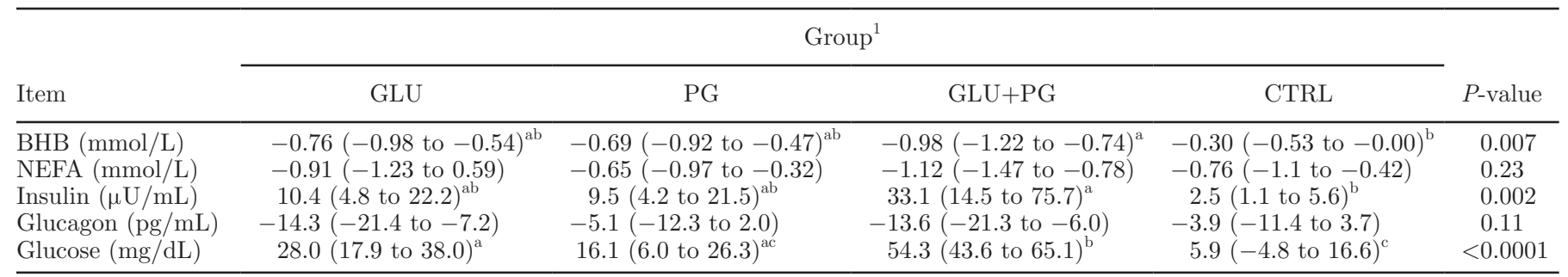

${ }^{\mathrm{a}-\mathrm{c}}$ Means with different superscript letters differ at a level of $P<0.05$ in mixed effects ANOVA and Tukey's posthoc test.

${ }^{1}$ Treatments consisted of $500 \mathrm{~mL}$ of $50 \%$ dextrose intravenously once daily for $3 \mathrm{~d}$ (GLU, $\mathrm{n}=9$ ), $300 \mathrm{~mL}$ of oral propylene glycol once daily for $3 \mathrm{~d}(\mathrm{PG}, \mathrm{n}=9), 300 \mathrm{~mL}$ of $50 \%$ dextrose intravenously and $300 \mathrm{~mL}$ of propylene glycol orally once daily for $3 \mathrm{~d}(\mathrm{GLU}+\mathrm{PG}, \mathrm{n}=8)$, or an untreated control (CTRL, $\mathrm{n}=8$ ).

753), 756 (701 to 810), and 774 (720 to 828$) \mathrm{kg}$ in the GLU, PG, GLU+PG, and CTRL group, respectively $(P=0.23)$. Body condition score at enrollment was not different between groups $(P=0.77)$ and the majority of cows had a BCS of $3.0(\mathrm{n}=14,41.2 \%)$ or $3.25(\mathrm{n}=$ $12,35.3 \%), 1$ animal (3\%) had a BCS of 2.5, 3 animals $(8.8 \%)$ had a BCS of 2.75, and the remaining 4 animals $(11.8 \%)$ had a BCS of 3.5.

Average BHB at enrollment was 1.39 (1.21 to 1.57), 1.37 (1.20 to 1.55 ), 1.47 (1.28 to 1.66 ), and 1.42 (1.23 to 1.61) $\mathrm{mmol} / \mathrm{L}$ for the GLU, PG, GLU+PG, and CTRL group, respectively $(P=0.86)$. Evaluation of statistical analysis and outlier diagnostics did not lead to violation of assumptions and thus all data were retained for analysis.

\section{Energy Metabolism Blood Parameters}

The mean (95\% CI) of the maximal response of BHB, NEFA, insulin, glucagon, and glucose concentrations at any time point in the first $24 \mathrm{~h}$ after treatment is presented in Table 2. Results of repeated measures analysis for whole blood BHB, plasma glucose, insulin, NEFA, and glucagon concentrations, as well as the molar insulin: glucagon ratio are depicted in Figure 1. A significant interaction of group and time was found for plasma glucose and insulin concentration $(P<0.001)$ as well as for the molar insulin:glucagon ratio $(P=$ 0.009 ) between $1 \mathrm{~h}$ and $\mathrm{d} 11$ relative to first treatment (Figure 1). Overall LSM for whole blood BHB concentrations between $1 \mathrm{~h}$ and $\mathrm{d} 11$ relative to first treatment were 1.11 (0.95 to 1.30), 1.26 (1.07 to 1.47), 0.96 (0.81 to 1.13 ), and 1.53 (1.30 to 1.80$) \mathrm{mmol} / \mathrm{L}$ for the GLU, PG, GLU+PG, and CTRL group, respectively $(P<0.0001)$. Differences for comparisons between individual groups were found for GLU and CTRL $(P=$ $0.001)$, GLU+PG and CTRL $(P<0.0001)$, as well as GLU+PG and PG $(P=0.02)$. Overall LSM for NEFA concentrations between $1 \mathrm{~h}$ and $\mathrm{d} 11$ relative to first treatment were 0.59 (0.50 to 0.69$), 0.68$ (0.58 to 0.79 ), $0.55(0.47$ to 0.65$)$, and 0.73 (0.62 to 0.86$) \mathrm{mmol} / \mathrm{L}$ in groups GLU, PG, GLU+PG, and CTRL, respectively $(P=0.001)$. Differences for comparisons between individual groups were found for GLU and CTRL $(P=$ $0.01)$, GLU + PG and CTRL $(P=0.001)$, as well as GLU $+\mathrm{PG}$ and PG $(P=0.03)$. Overall LSM for glucagon concentrations between $1 \mathrm{~h}$ and $\mathrm{d} 11$ relative to first treatment were 124 (119 to 128), 128 (124 to 133), 124 (120 to 129), and 132 (126 to 136) pg/mL for groups GLU, PG, GLU+PG, and CTRL, respectively $(P=0001)$. Differences for comparisons between individual groups were found for GLU and CTRL $(P=$ $0.0003)$, GLU and PG $(P=0.03)$, and GLU+PG and CTRL $(P=0.003)$.

\section{Plasma Electrolytes}

Results of repeated measures analysis of plasma electrolyte concentration are shown in Figure 2. No interaction between time and group was found. No differences were observed between groups in the concentrations of sodium, chloride, calcium, magnesium, phosphate, and potassium between 1 and $72 \mathrm{~h}$ relative to first treatment.

\section{Hematology and Red Blood Cell Morphology}

Results of the hemogram at 0 and $72 \mathrm{~h}$ are shown in Table 3. Red blood cell counts, hematocrit, and hemoglobin concentration decreased slightly between the 2 measurements across all groups. No group or time changes were detected in the red blood cell indices mean corpuscular volume, mean corpuscular hemoglobin, mean corpuscular hemoglobin concentration, and red blood cell distribution width, as well as in total leukocyte counts and differential white blood cell counts except a decline in monocytes at $72 \mathrm{~h}$ compared with 0 $\mathrm{h}$ in all groups. No microscopic evidence was observed 


\section{CTRL $\approx$ GLU $\approx$ PG $\approx$ GLU+PG}

A

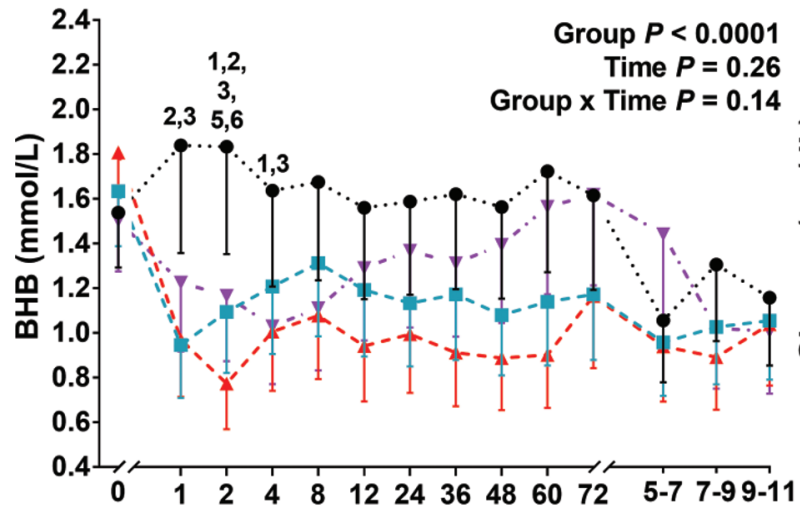

C
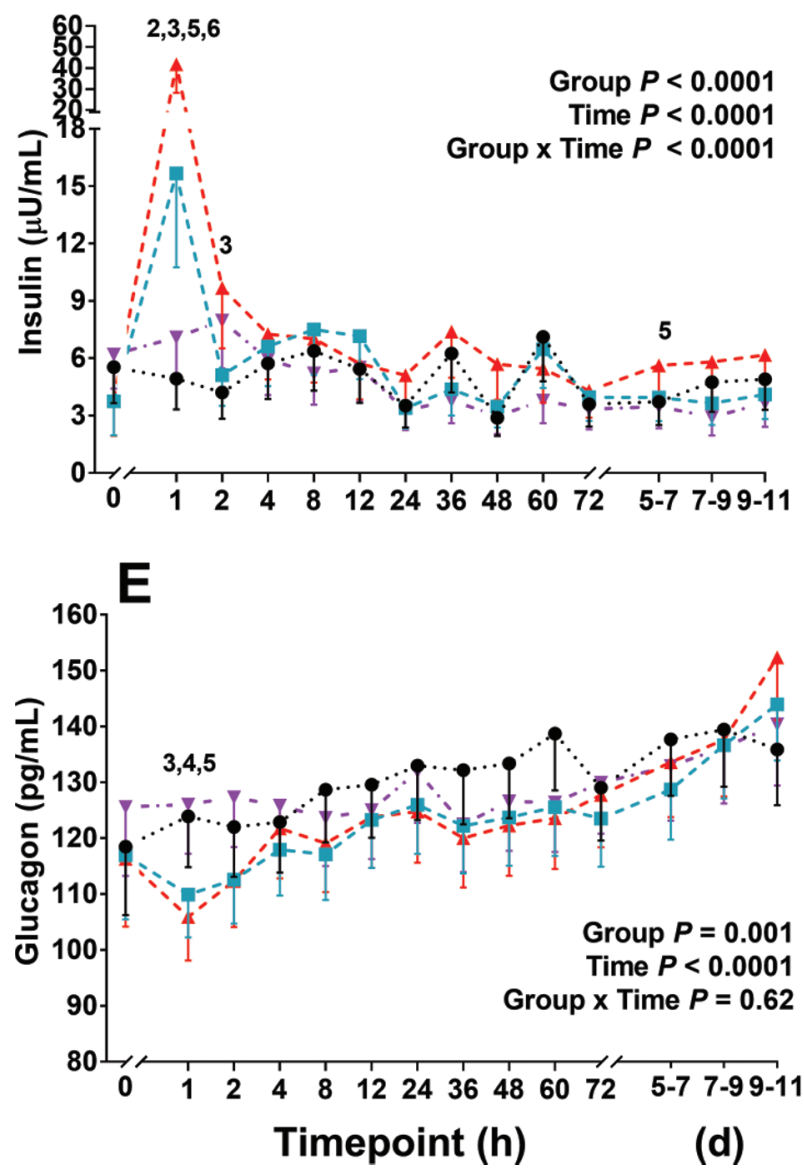

B
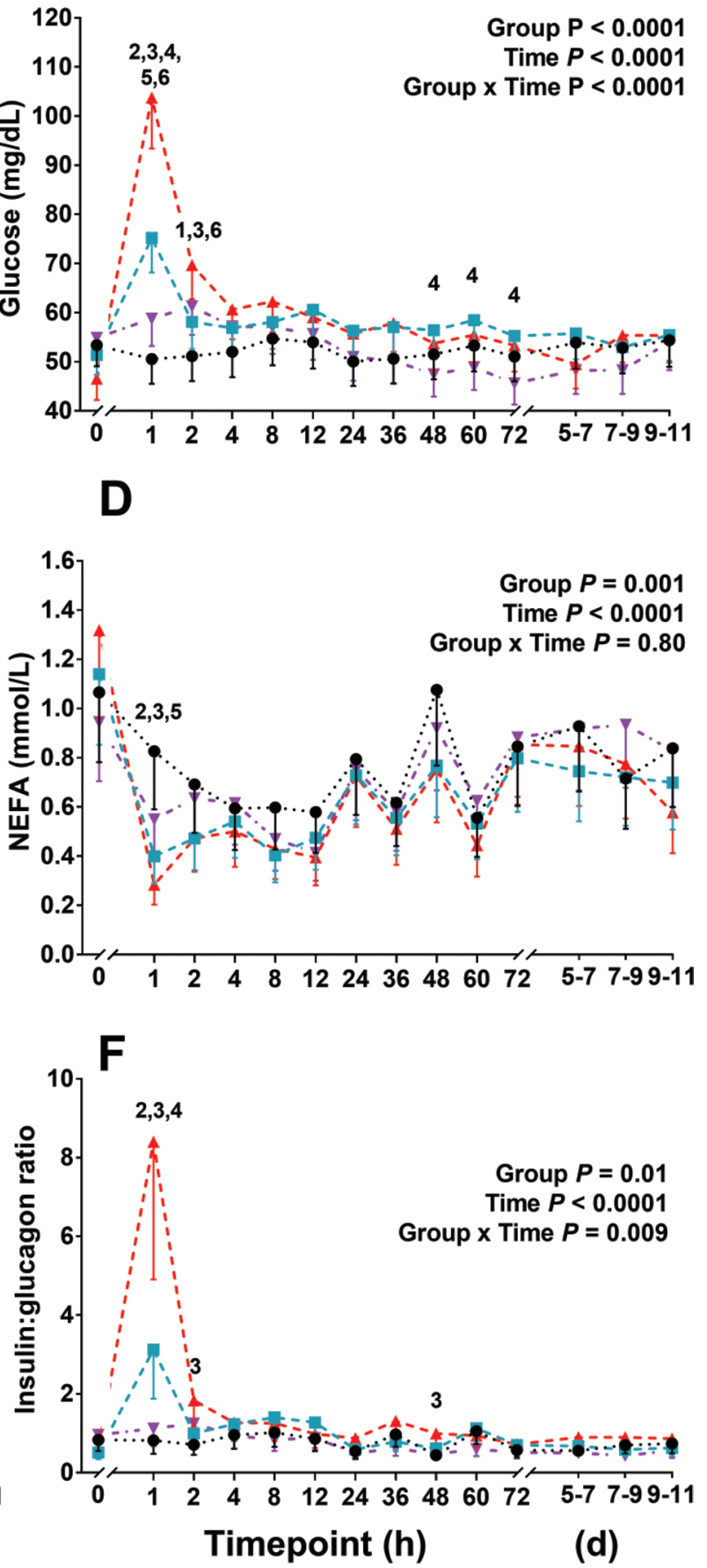

Figure 1. Least squares means and lower $95 \%$ CI bars for repeated measurements of plasma concentrations of BHB (A), glucose (B), insulin (C), nonesterified fatty acids (NEFA; D), glucagon (E), as well as molar insulin:glucagon ratio (F) in early postpartum hyperketonemic cows randomly assigned to treatments: (1) GLU: $\mathrm{n}=9,500 \mathrm{~mL}$ of a $50 \%$ glucose solution i.v. immediately following time points 0,24 , and 48 h; (2) PG: $\mathrm{n}=9,300 \mathrm{~mL}$ of propylene glycol orally immediately following time points 0,24 , and $48 \mathrm{~h} ;(3)$ GLU+PG: $\mathrm{n}=8,500 \mathrm{~mL}$ of a $50 \%$ glucose solution i.v. and $300 \mathrm{~mL}$ of propylene glycol orally immediately following time points 0,24 , and $48 \mathrm{~h}$; or (4) CTRL: $\mathrm{n}=8$, untreated control group. Baseline concentrations included in model as covariate. $P$-values for the fixed effects of group, time point, and group and time point interaction are included in each graph. Least squares means for baseline $(0 \mathrm{~h})$ from mixed-effects ANOVA. Pairwise comparison among groups with Sidak's corrected $P<0.05$ marked with the following numbers: ${ }^{1} \mathrm{CTRL}$ and PG; ${ }^{2} \mathrm{CTRL}$ and GLU; ${ }^{3} \mathrm{CTRL}$ and GLU+PG; ${ }^{4} \mathrm{PG}$ and GLU; ${ }^{5} \mathrm{PG}$ and $\mathrm{GLU}+\mathrm{PG} ;{ }^{6} \mathrm{GLU}$ and GLU+PG. Color version available online. 


\section{CTRL $\neq$ GLU $\neq$ PG $\approx$ GLU+PG}

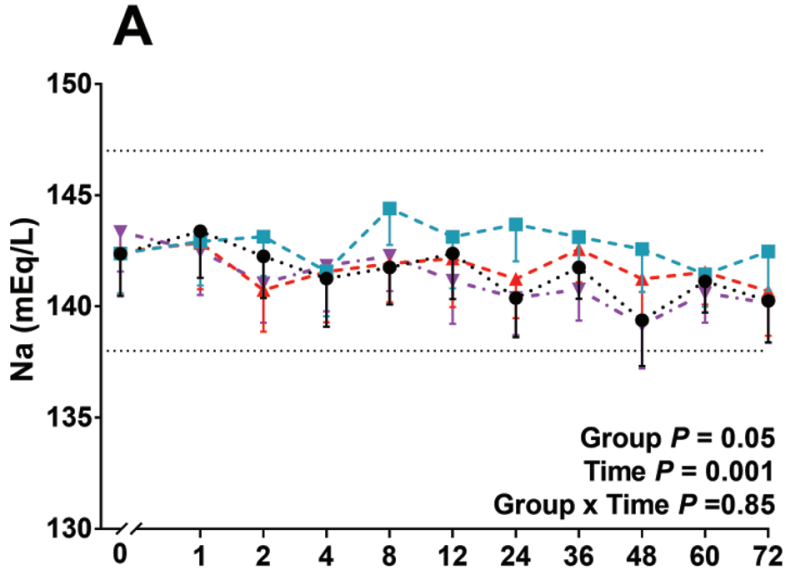

B
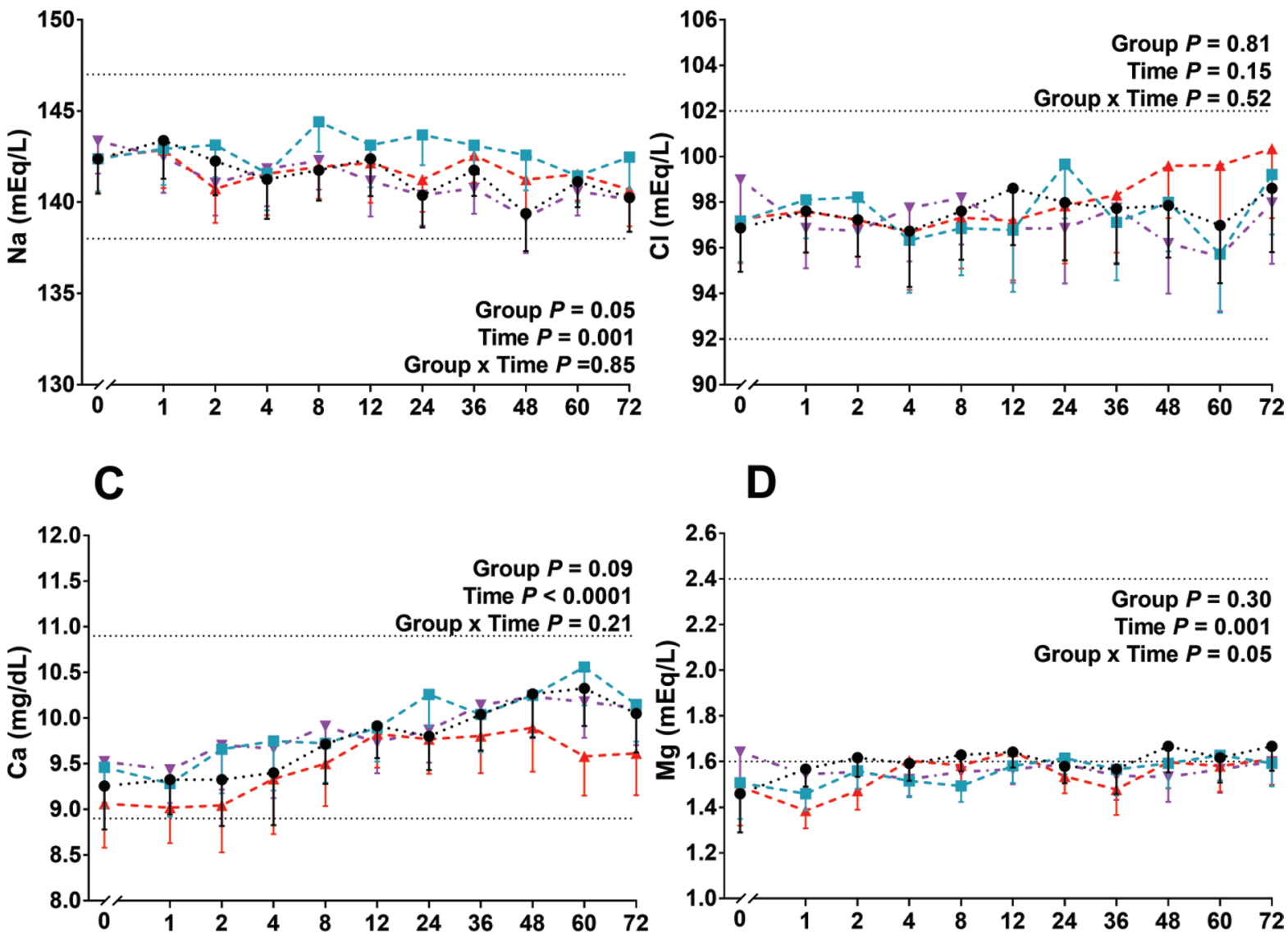

$\mathbf{E}$
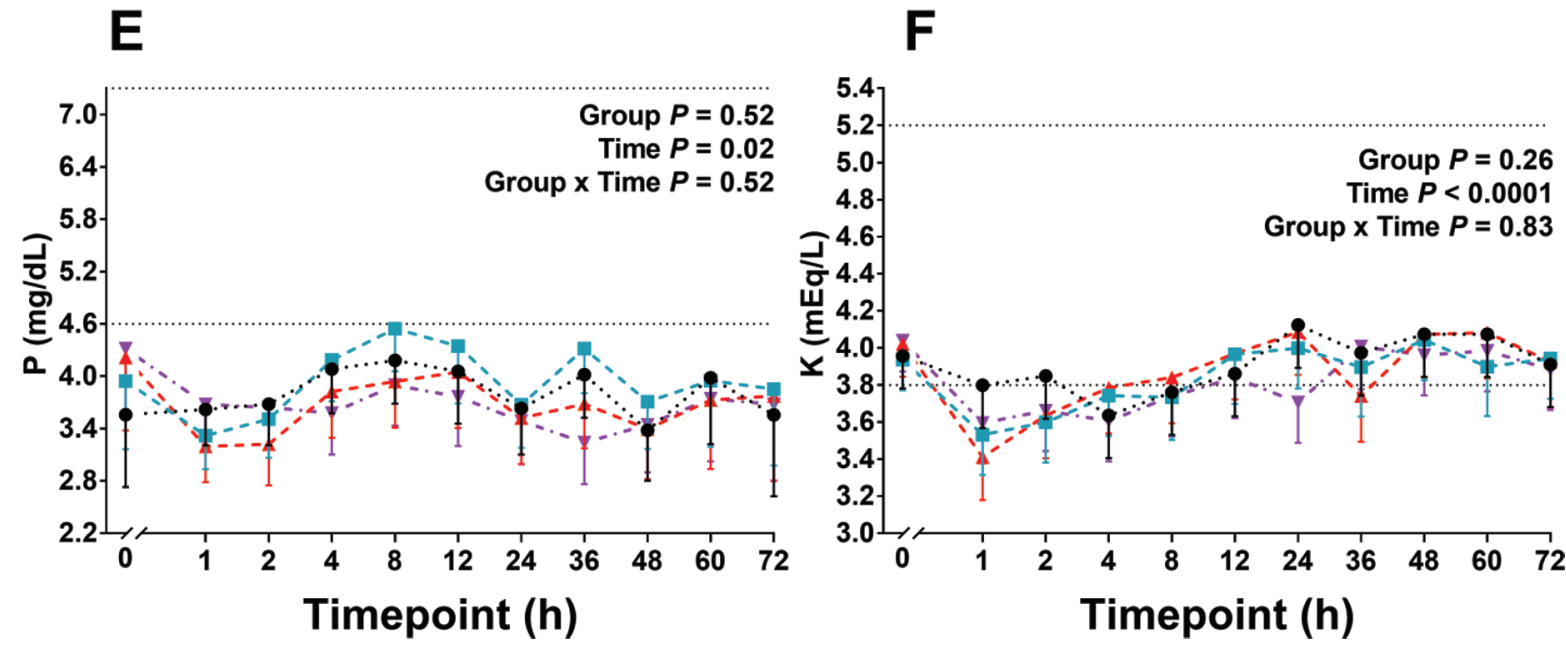

Figure 2. Least squares means and lower 95\% CI bars for repeated measurements of plasma concentrations of sodium (A), chloride (B), calcium (C), magnesium (D), phosphate (E), as well as potassium (F) in early postpartum hyperketonemic cows randomly assigned to treatments: (1) GLU: $\mathrm{n}=9,500 \mathrm{~mL}$ of a $50 \%$ glucose solution i.v. immediately following time points 0,24 , and $48 \mathrm{~h} ;(2) \mathrm{PG}: \mathrm{n}=9,300 \mathrm{~mL}$ of propylene glycol orally immediately following time points 0,24 , and $48 \mathrm{~h} ;(3)$ GLU+PG: $\mathrm{n}=8,500 \mathrm{~mL}$ of a $50 \%$ glucose solution i.v. and $300 \mathrm{~mL}$ of propylene glycol orally immediately following time points 0,24 , and $48 \mathrm{~h}$; or (4) CTRL: $\mathrm{n}=8$, untreated control group. Baseline concentrations were included in model as covariate. The $P$-values for the fixed effects of group, time point, and group and time point interaction are included in each graph. Least squares means for baseline $(0 \mathrm{~h})$ from mixed-effects ANOVA. Upper and lower reference range shown as dotted lines. Color version available online. 


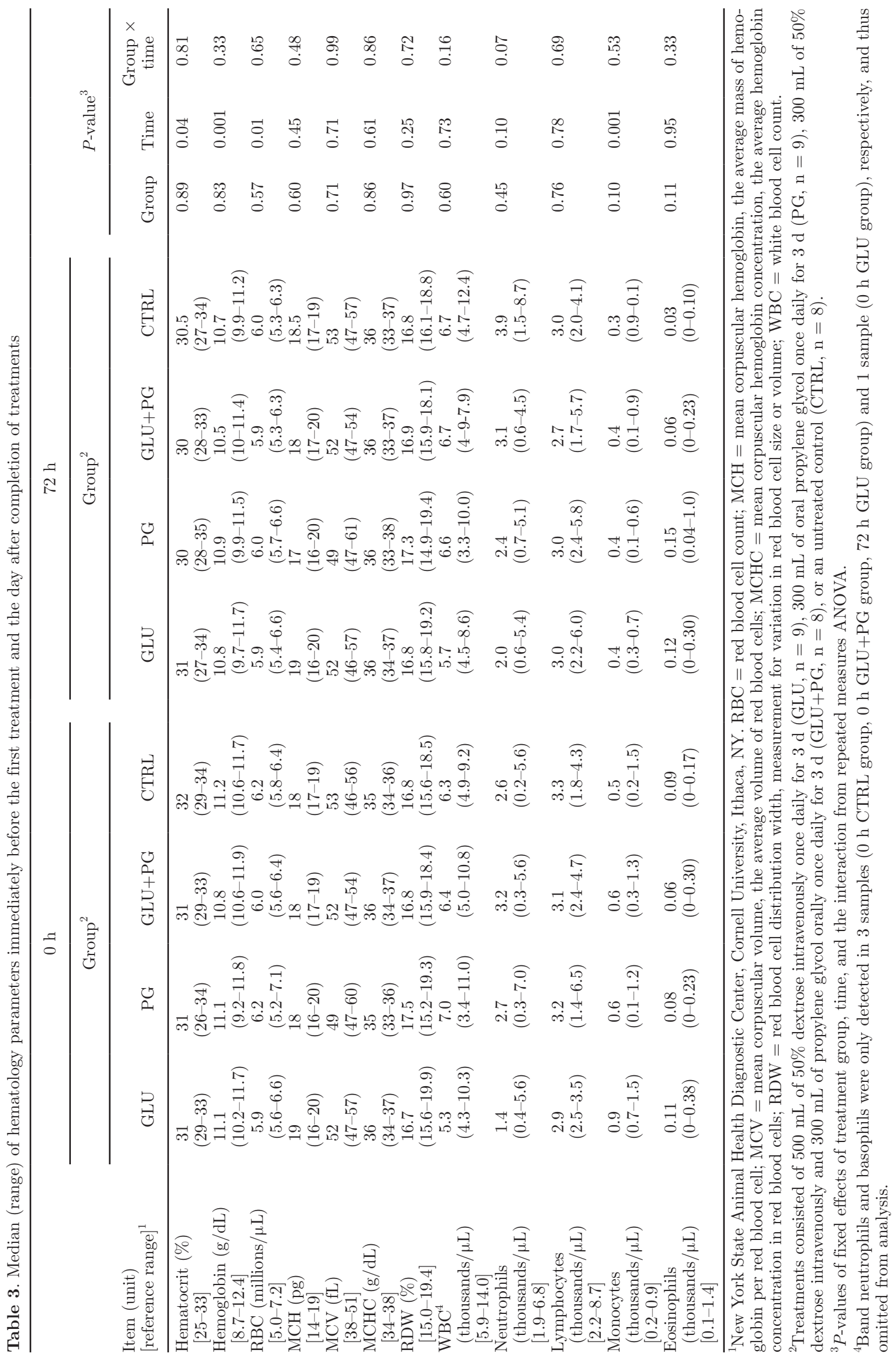




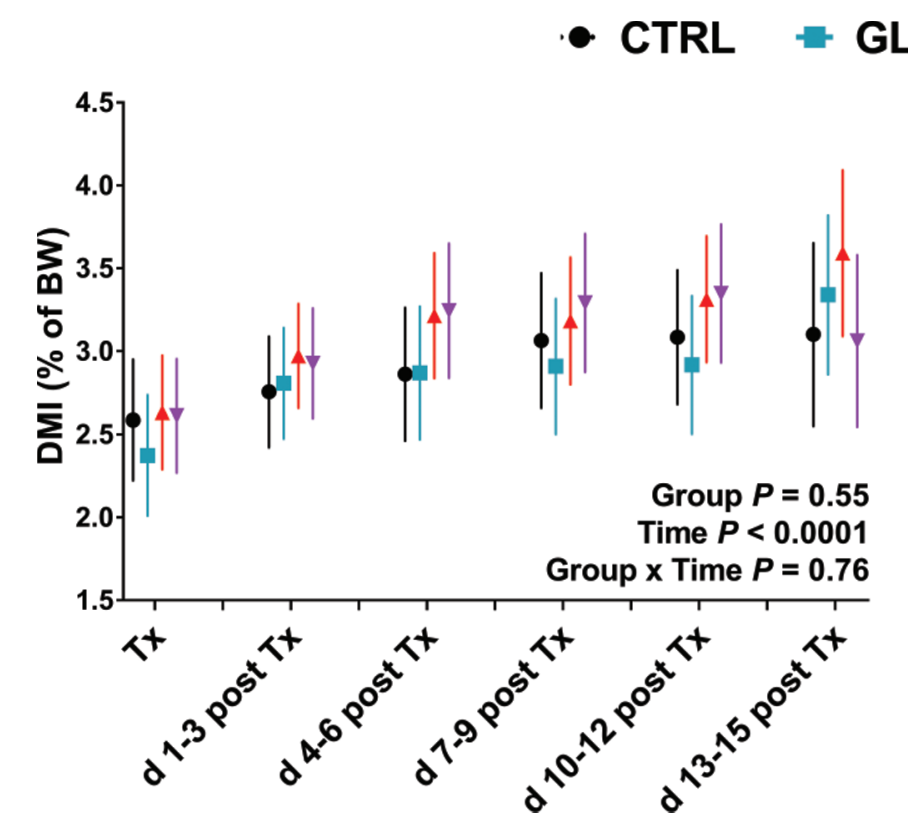

\section{GLU $\approx$ PG $\approx$ GLU+PG}

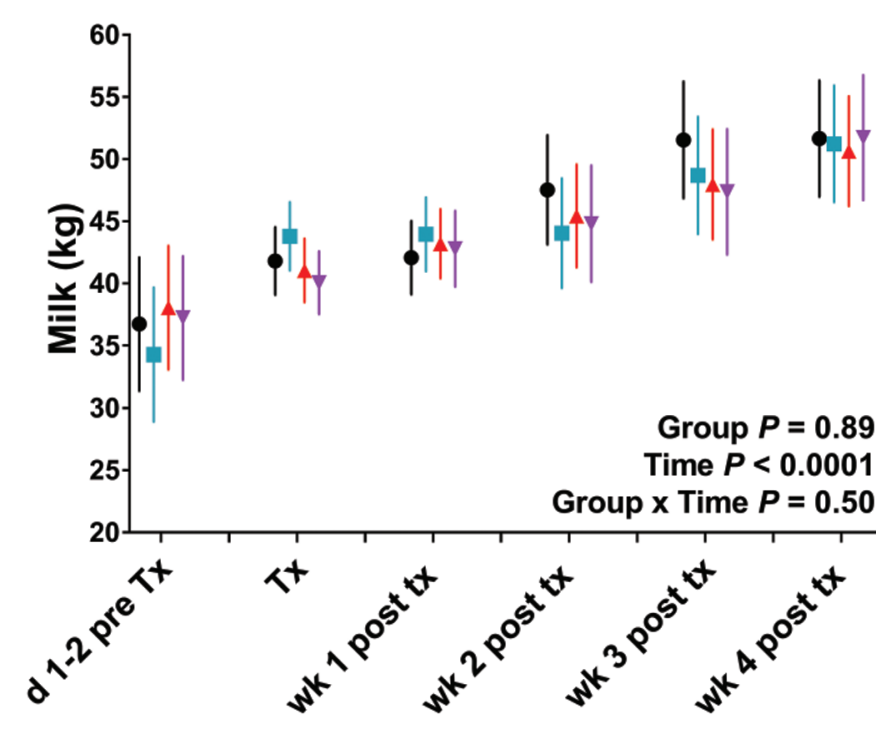

Figure 3. Least squares means and $95 \%$ CI for repeated measurements of DMI in percentage of BW (left) during the study period and kilograms of milk yield (right) before, during, and for the 4-wk period after treatment (Tx) in early postpartum hyperketonemic cows randomly assigned to treatments: (1) GLU: $\mathrm{n}=9,500 \mathrm{~mL}$ of a $50 \%$ glucose solution i.v. immediately following time points 0,24 , and $48 \mathrm{~h} ;(2)$ PG: $\mathrm{n}=9$, 300 $\mathrm{mL}$ of propylene glycol orally immediately following time points 0,24 , and $48 \mathrm{~h}$; (3) GLU+PG: $\mathrm{n}=8,500 \mathrm{~mL}$ of a $50 \%$ glucose solution i.v. and $300 \mathrm{~mL}$ of propylene glycol orally immediately following time points 0,24 , and $48 \mathrm{~h}$; or (4) CTRL: $\mathrm{n}=8$, untreated control group. The $P$-values for the fixed effects of group, time point, and group and time point interaction are included in each graph. Color version available online.

of red blood cell lysis, fragmentation, or regeneration. A mild degree of echinocytosis, anisocytosis, or both was sporadically noted across all treatment groups.

\section{DMI and Milk Production}

Intake of cows did not differ between groups at any time during the study $(P=0.55)$, but increased over the time course of the study $(P<0.0001$; Figure 3$)$. Milk yield was not different between groups in the $2 \mathrm{~d}$ preceding enrollment $(P=0.76)$, increased in all groups over time $(P<0.0001)$, and did not differ during treatments or in the 4 -wk period following treatments $(P=$ 0.89 ; Figure 3).

\section{Health Events}

One cow in the PG group developed an LDA on $\mathrm{d}$ 9 after enrollment, and 1 cow in the PG group had a BHB concentration of $5.0 \mathrm{mmol} / \mathrm{L}$ at $72 \mathrm{~h}$ and showed marked depression; both animals were removed from the study at this time and treated according to farm standard operating procedures. No other clinical signs of ketosis were observed during the study, and none of the animals became recumbent or showed any signs of muscle weakness during or after treatments.

\section{DISCUSSION}

\section{Effects of Treatments on Reduction in BHB Concentration}

Our primary objective was to compare the effect of different treatment strategies commonly used on dairy farms on the decrease in blood BHB concentrations of early-lactation hyperketonemic cows. We showed that treatment with a combination of glucose and propylene glycol reduced the BHB concentration for a longer period and to a lower concentration than both treatments alone. The decrease in BHB concentration had its nadir at $1 \mathrm{~h}$ after treatment when cows were treated with glucose alone, compared with $4 \mathrm{~h}$ after treatment when treating with propylene glycol, and at $2 \mathrm{~h}$ for the combination treatment. Over the whole study period, the combination treatment decreased BHB concentrations to the greatest extent compared with the control group. We attribute this to the different pathways targeted in peripheral and liver metabolism by glucose and propylene glycol, the greater difference in both insulin and glucagon concentrations observed with the combination treatment, and the corresponding greater magnitude in suppression of lipolysis and hepatic ketogenesis (Brockman, 1979), which was also reflected in the greater overall reduction in NEFA concentrations throughout 
the study. To our knowledge this is the first controlled study comparing this combination treatment with either propylene glycol or glucose treatments alone, and with an untreated control. It is possible that cows with more pronounced hyperketonemia (e.g., concentrations of $\mathrm{BHB} \geq 1.2 \mathrm{mmol} / \mathrm{L}$ ) may benefit in particular from the combination treatment due to its more prolonged duration and greater magnitude of physiological effects. This hypothesis remains to be tested in a study with a larger range of $\mathrm{BHB}$ concentrations of hyperketonemic animals at enrollment than those included herein.

\section{Effects of Treatments on NEFA, Insulin, Glucose, and Glucagon Concentrations}

Besides the transient effect on BHB after treatment with propylene glycol, no differences were found at later time points, and overall concentrations of NEFA, insulin, and glucagon were not altered by propylene glycol treatment alone when compared with untreated control cows. Pickett et al. (2003) drenched cows for the first $3 \mathrm{~d}$ postpartum with $500 \mathrm{~mL}$ of propylene glycol and found that concentrations of BHB tended to decrease and insulin concentrations in plasma were not significantly altered by this treatment when sampling cows daily before treatments, whereas NEFA concentrations decreased compared with untreated controls. Differences in observations between our study and the study by Pickett et al. (2003) could be due to the use of propylene glycol in cows that were not hyperketonemic and treated immediately postpartum as opposed to choosing cows with hyperketonemia. We saw an average increase in glucose concentrations at 2 $\mathrm{h}$ after treatment by approximately $7 \mathrm{mg} / \mathrm{dL}$ in cows drenched with propylene glycol which is in accordance with findings reported by Miyoshi et al. (2001) who drenched postpartum dairy cows daily between 7 to 42 DIM with $500 \mathrm{~mL}$ of propylene glycol and showed a similar increase in glucose 90 min after administration. The increase in glucose after propylene glycol dosing is explained by the metabolization to lactate and then to pyruvate, as well as the uptake of propionate from the rumen (Nielsen and Ingvartsen, 2004). The peak of the effect on plasma glucose varies between studies but is expected to occur in the first $4 \mathrm{~h}$ after treatment (Nielsen and Ingvartsen, 2004), which is consistent with our findings.

Despite the decrease in BHB concentrations after treatment with propylene glycol, we failed to detect a difference in NEFA, insulin, and glucagon concentrations from untreated cows overall, and maximal responses in these metabolites did not differ from control. Although there were differences in study design, sampling protocol, and analytical methods, we found the maximal response of reduction of BHB concentrations as well as increase in insulin and glucose concentrations observed in this study to be very similar to that reported by Piantoni and Allen (2015) in ruminally cannulated cows in early lactation that were given 300 $\mathrm{mL}$ of propylene glycol. It is possible that a short-lived effect of treatment of higher magnitude was not detected with our sampling timeframe, but contributed to the reduction in ketogenesis. We may also have failed to observe differences in biologically important effects of small magnitude in these secondary outcomes (NEFA, insulin, glucose, glucagon concentrations) in our analysis due to the relatively small sample size that was based on a larger expected response in BHB reduction after treatment, and the potential for greater variability in concentrations of these analytes between cows in the same treatment group. In addition, the hepatic pathways targeted by propylene glycol that lead to a decrease in ketogenesis (Nielsen and Ingvartsen, 2004) do not necessarily also lead to the same magnitude in response to other energy metabolites. An alternative explanation why we failed to see an increase in insulin concentrations with a subsequent reduction in circulating NEFA compared with previous studies performed on cows in different stages of lactation (Chung et al., 2009) or nonlactating animals (Grummer et al., 1994; Christensen et al., 1997) is that we specifically chose to test the effect of treatment in early-lactation hyperketonemic animals known to have a reduced insulin response to a glucose challenge (Hove, 1978; Sakai et al., 1996; Mann et al., 2016). Previous research has also failed to detect an increase in insulin concentrations and a decrease in BHB concentrations in fresh cows after treatment in the immediate peripartum period with propylene glycol (Formigoni et al., 1996).

Given the moderate responses after treatment with propylene glycol observed in this study and the available data on the positive effects of propylene glycol treatment for hyperketonemic cows in early lactation generated in a large field trial (McArt et al., 2011), it is surprising that treatment effects on BHB concentration and other plasma analytes in the PG group were not more pronounced. Treatment of hyperketonemic cows in early lactation reduced the hazard of progressing to clinical ketosis and treated cows were 1.5 times more likely to resolve hyperketonemia compared with untreated hyperketonemic control cows (McArt et al., 2011). It remains to be shown if the greater treatment effect for GLU and GLU+PG groups in this study with intense sampling protocol would translate into an equally greater effect on resolution of hyperketonemia and biologically significant effects on health outcomes and production when compared with propylene glycol in a comparable field study. 
We previously showed that an intravenous bolus of glucose led to an increase in insulin concentrations with a peak approximately 10 min after administration and to a nadir in NEFA concentrations approximately $45 \mathrm{~min}$ after treatment with a return to baseline concentrations within 2 h (Mann et al., 2016). Glucose and insulin concentrations at $60 \mathrm{~min}$ after glucose treatment in the current study were comparable to our previous study at the $4 \mathrm{~d}$ postpartum time point, and glucagon and NEFA concentrations were decreased in cows treated with glucose compared with control cows. The effects of intravenous glucose administration on NEFA suppression, the decrease in glucagon and increase in glucose and insulin were potentiated by the combination of intravenous glucose with oral propylene glycol, explaining the greater decline in BHB concentration. We did not observe a negative effect of glucose administration on DMI when administered alone or in combination with propylene glycol. Previous studies administering glucose as a continuous intravenous infusion of a total of $1,000 \mathrm{~g}$ of glucose/d over the first $12 \mathrm{~d}$ postpartum (Brown and Allen, 2013) or as an intra-abomasal infusion of 1,500 g/d for the first $29 \mathrm{~d}$ postpartum (Larsen and Kristensen, 2009) showed decreased DMI regardless of route of continuous administration. The difference between the results is likely attributable to the administration of glucose in a bolus form in our study.

\section{Effects on Electrolytes}

There is concern that the standard treatment of 500 $\mathrm{mL}$ of $50 \%$ dextrose is excessive and may have detrimental effects, including causation of electrolyte imbalances following an intravenous bolus infusion (Wagner and Schimek, 2010; Gordon et al., 2013). In particular, the physiological decline in plasma phosphate concentration due to an insulin-dependent intracellular shift is of interest as clinical hypophosphatemia may be associated with muscle weakness and recumbency (Grünberg, 2014). Bolus infusion of $500 \mathrm{~mL}$ of a $50 \%$ dextrose infusion lead to an average decline in plasma phosphate ranging from 1.1 to $1.5 \mathrm{mg} / \mathrm{dL}$ within $60 \mathrm{~min}$ after bolus infusion in 2 separate studies (Grünberg et al., 2006, 2011). A similar decrease in phosphate was also reported after the infusion of 500 and 1,000 $\mathrm{mL}$ of a $50 \%$ dextrose solution in bolus form in healthy early postpartum cows with a nadir at $1 \mathrm{~h}$ posttreatment and return to pretreatment concentrations by $12 \mathrm{~h}$ (Wagner and Schimek, 2010). Phosphate concentrations in our study declined numerically by $0.6,0.6$, and $1.0 \mathrm{mg} /$ $\mathrm{dL}$ at $60 \mathrm{~min}$ after treatment in the GLU, PG, and GLU+PG group, respectively; however, phosphate concentrations were not different from the control group. Overall phosphate concentrations were below the refer- ence range in all groups before and during treatment. The usefulness of the reference range for periparturient cows has been questioned as most healthy postpartum cows are classified as hypophosphatemic (Grünberg, 2014). It is however possible that hyperketonemic cows show lower plasma concentrations of phosphate due to lower feed intake (Grünberg et al., 2005) compared with nonhyperketonemic herd mates. The absence of changes in sodium, chloride, calcium, magnesium, and potassium concentrations after treatment with 500 $\mathrm{mL}$ of $50 \%$ dextrose is consistent with the findings in the study by Wagner and Schimek (2010). In conclusion, our data suggest that a bolus of $500 \mathrm{~mL}$ of a $50 \%$ dextrose solution alone or in combination does not have clinically relevant detrimental effects on plasma mineral balance.

\section{Effects on Red Blood Cell Morphology}

A secondary objective was to describe possible treatment effects on red blood cell morphology. Nielsen and Ingvartsen (2004) reported rapid shallow breathing, ataxia, salivation, and depression in cows fed a ration with added propylene glycol and hypothesize that hyperventilation may be due to destruction of red blood cells. However, Bertram et al. (2009) observed severe dyspnea $12 \mathrm{~min}$ after consumption of concentrate with propylene glycol and demonstrated a decrease in oxygen saturation. Toxic effects of propylene glycol such as hemoglobinuria, Heinz body, and reticulocyte formation have been reported for other species after intravenous injection of an aqueous solution of $20 \%$ propylene glycol (Potter, 1958) or supplementation in the feed (Bauer et al., 1992). We observed no toxic effect of propylene glycol on red blood cell indices or changes in red blood cell morphology, suggesting an increase in red blood cell lysis or active regeneration. We conclude that there is no evidence that treatment with propylene glycol alone or in combination with glucose over a course of $3 \mathrm{~d}$ and in the amount of $300 \mathrm{~mL}$ once per day causes visually detectable damage to red blood cells or evidence of increased red blood cell production. The slight decrease in hematocrit that occurred equally in all groups between the 2 sampling time points may be the result of blood loss from the first liver biopsy or part of the physiological decline in hematocrit in early lactation (Wohlt et al., 1984). Regardless of the underlying etiology, the minimal change likely lacks biological significance.

\section{CONCLUSIONS}

We conclude that treatments varied in the magnitude of decreasing blood BHB concentrations in hyperke- 
tonemic postpartum cows. The greatest decline was observed with a combination of glucose and propylene glycol without negatively affecting blood mineral concentrations or DMI, and in the absence of toxic effects on red blood cells.

\section{ACKNOWLEDGMENTS}

This material is based on work that is supported by the National Institute of Food and Agriculture, US Department of Agriculture, Animal Health and Disease Research Program under award number 36100-03618, made available to the College of Veterinary Medicine, Cornell University. We thank Pharmadoc, Germany, and TaiDoc, Taiwan, for the donation of BHB meters and strips used in this study. We acknowledge the support of the Endocrinology Laboratory of the New York State Animal Health Diagnostic Center (Ithaca), in particular the invaluable assistance of Ned Place, Steve Lamb, and Valerie Salerno with insulin and glucagon measurements for this study. The authors thank Charlene Ryan, Stephanie Tarlowe, and Jamie Horstmann (Cornell University, Ithaca, NY) for their invaluable assistance with data collection. We also thank the staff at the research dairy for the care of the animals used in this study.

\section{REFERENCES}

Bach, K. D., W. Heuwieser, and J. A. McArt. 2016. Technical note: Comparison of 4 electronic handheld meters for diagnosing hyperketonemia in dairy cows. J. Dairy Sci. 99:9136-9142. https://doi. org/10.3168/jds.2016-11077.

Bauer, M. C., D. J. Weiss, and V. Perman. 1992. Hematological alterations in kittens induced by 6 and $12 \%$ dietary propylene glycol. Vet. Hum. Toxicol. 34:127-131.

Berge, A. C., and G. Vertenten. 2014. A field study to determine the prevalence, dairy herd management systems, and fresh cow clinical conditions associated with ketosis in western European dairy herds. J. Dairy Sci. 97:2145-2154. https://doi.org/10.3168/ jds.2013-7163.

Bertram, H. C., B. O. Petersen, J. O. Duus, M. Larsen, B. M. Raun, and N. B. Kristensen. 2009. Proton nuclear magnetic resonance spectroscopy based investigation on propylene glycol toxicosis in a Holstein cow. Acta Vet. Scand. 51:25. https://doi. org/10.1186/1751-0147-51-25.

Brockman, R. P. 1979. Roles for insulin and glucagon in the development of ruminant ketosis-A review. Can. Vet. J. 20:121-126.

Brown, W. E., and M. S. Allen. 2013. Effects of intrajugular glucose infusion on feed intake, milk yield, and metabolic responses of early postpartum cows fed diets varying in protein and starch concentration. J. Dairy Sci. 96:7132-7142. 10.3168/jds.2013-6636.

Christensen, J. O., R. R. Grummer, F. E. Rasmussen, and S. J. Bertics. 1997. Effect of method of delivery of propylene glycol on plasma metabolites of feed-restricted cattle. J. Dairy Sci. 80:563-568. https://doi.org/10.3168/jds.S0022-0302(97)75971-X.

Chung, Y. H., C. M. Martinez, N. E. Brown, T. W. Cassidy, and G. A. Varga. 2009. Ruminal and blood responses to propylene glycol during frequent feeding. J. Dairy Sci. 92:4555-4564. https://doi. org $/ 10.3168 /$ jds.2009-2131.

Duffield, T. F., K. D. Lissemore, B. W. McBride, and K. E. Leslie. 2009. Impact of hyperketonemia in early lactation dairy cows on health and production. J. Dairy Sci. 92:571-580. https://doi. org/10.3168/jds.2008-1507.

Formigoni, A., M. C. Cornil, A. Prandi, A. Mordenti, A. Rossi, D. Portetelle, and R. Renaville. 1996. Effect of propylene glycol supplementation around parturition on milk yield, reproduction performance and some hormonal and metabolic characteristics in dairy cows. J. Dairy Res. 63:11-24.

Gordon, J. L., S. J. Leblanc, and T. F. Duffield. 2013. Ketosis treatment in lactating dairy cattle. Vet. Clin. North Am. Food Anim. Pract. 29:433-445. https://doi.org/10.1016/j.cvfa.2013.03.001.

Grummer, R. R., J. C. Winkler, S. J. Bertics, and V. A. Studer. 1994 Effect of propylene glycol dosage during feed restriction on metabolites in blood of prepartum Holstein heifers. J. Dairy Sci. 77:3618 3623. https://doi.org/10.3168/jds.S0022-0302(94)77306-9.

Grünberg, W. 2014. Treatment of phosphorus balance disorders. Vet. Clin. North Am. Food Anim. Pract. 30:383-408. https://doi. org/10.1016/j.cvfa.2014.03.002.

Grünberg, W., P. Constable, U. Schroder, R. Staufenbiel, D. Morin, and M. Rohn. 2005. Phosphorus homeostasis in dairy cows with abomasal displacement or abomasal volvulus. J. Vet. Intern. Med. 19:894-898.

Grünberg, W., S. S. Donkin, and P. D. Constable. 2011. Periparturient effects of feeding a low dietary cation-anion difference diet on acidbase, calcium, and phosphorus homeostasis and on intravenous glucose tolerance test in high-producing dairy cows. J. Dairy Sci. 94:727-745. https://doi.org/10.3168/jds.2010-3230.

Grünberg, W., D. E. Morin, J. K. Drackley, and P. D. Constable. 2006. Effect of rapid intravenous administration of $50 \%$ dextrose solution on phosphorus homeostasis in postparturient dairy cows. J. Vet. Intern. Med. 20:1471-1478.

Holtenius, K., K. Sternbauer, and P. Holtenius. 2000. The effect of the plasma glucose level on the abomasal function in dairy cows. J. Anim. Sci. 78:1930-1935.

Hove, K. 1978. Insulin secretion in lactating cows: Responses to glucose infused intravenously in normal, ketonemic, and starved animals. J. Dairy Sci. 61:1407-1413. https://doi.org/10.3168/jds. S0022-0302(78)83742-4.

Larsen, M., and N. B. Kristensen. 2009. Effect of abomasal glucose infusion on splanchnic and whole-body glucose metabolism in periparturient dairy cows. J. Dairy Sci. 92:1071-1083. 10.3168/ jds.2008-1453.

Lean, I. J., R. Van Saun, and P. J. DeGaris. 2013. Energy and protein nutrition management of transition dairy cows. Vet. Clin. North Am. Food Anim. Pract. 29:337-366. 10.1016/j.cvfa.2013.03.005.

Mann, S., F. A. Yepes, M. Duplessis, J. J. Wakshlag, T. R. Overton, B. P. Cummings, and D. V. Nydam. 2016. Dry period plane of energy: Effects on glucose tolerance in transition dairy cows. J. Dairy Sci. 99:701-717. https://doi.org/10.3168/jds.2015-9908.

Mann, S., F. A. Yepes, T. R. Overton, J. J. Wakshlag, A. L. Lock, C. M. Ryan, and D. V. Nydam. 2015. Dry period plane of energy: Effects on feed intake, energy balance, milk production, and composition in transition dairy cows. J. Dairy Sci. 98:3366-3382. https:// doi.org/10.3168/jds.2014-9024.

McArt, J. A., D. V. Nydam, and G. R. Oetzel. 2012a. A field trial on the effect of propylene glycol on displaced abomasum, removal from herd, and reproduction in fresh cows diagnosed with subclinical ketosis. J. Dairy Sci. 95:2505-2512. https://doi.org/10.3168/ jds.2011-4908.

McArt, J. A., D. V. Nydam, and G. R. Oetzel. 2012b. Epidemiology of subclinical ketosis in early lactation dairy cattle. J. Dairy Sci. 95:5056-5066. https://doi.org/10.3168/jds.2012-5443.

McArt, J. A., D. V. Nydam, and G. R. Oetzel. 2013. Dry period and parturient predictors of early lactation hyperketonemia in dairy cattle. J. Dairy Sci. 96:198-209. https://doi.org/10.3168/jds.20125681.

McArt, J. A., D. V. Nydam, P. A. Ospina, and G. R. Oetzel. 2011. A field trial on the effect of propylene glycol on milk yield and resolution of ketosis in fresh cows diagnosed with subclinical ketosis. J. Dairy Sci. 94:6011-6020. https://doi.org/10.3168/jds.2011-4463.

McArt, J. A., D. V. Nydam, and M. W. Overton. 2015. Hyperketonemia in early lactation dairy cattle: A deterministic estimate of 
component and total cost per case. J. Dairy Sci. 98:2043-2054. https://doi.org/10.3168/jds.2014-8740.

Miyoshi, S., J. L. Pate, and D. L. Palmquist. 2001. Effects of propylene glycol drenching on energy balance, plasma glucose, plasma insulin, ovarian function and conception in dairy cows. Anim. Reprod. Sci. 68:29-43.

Nielsen, N. I., and K. L. Ingvartsen. 2004. Propylene glycol for dairy cows: A review of the metabolism of propylene glycol and its effects on physiological parameters, feed intake, milk production and risk of ketosis. Anim. Feed Sci. Technol. 115:191-213. https://doi. org/10.1016/j.anifeedsci.2004.03.008.

Ospina, P. A., D. V. Nydam, T. Stokol, and T. R. Overton. 2010. Evaluation of nonesterified fatty acids and beta-hydroxybutyrate in transition dairy cattle in the northeastern United States: Critical thresholds for prediction of clinical diseases. J. Dairy Sci. 93:546-554. https://doi.org/10.3168/jds.2009-2277.

Piantoni, P., and M. S. Allen. 2015. Evaluation of propylene glycol and glycerol infusions as treatments for ketosis in dairy cows. J. Dairy Sci. 98:5429-5439. https://doi.org/10.3168/jds.2015-9476.

Pickett, M. M., M. S. Piepenbrink, and T. R. Overton. 2003. Effects of propylene glycol or fat drench on plasma metabolites, liver composition, and production of dairy cows during the periparturient period. J. Dairy Sci. 86:2113-2121. 10.3168/jds.S00220302(03)73801-6.

Potter, B. J. 1958. Haemoglobinuria caused by propylene glycol in sheep. Br. J. Pharmacol. Chemother. 13:385-389.
Roberts, T., N. Chapinal, S. J. Leblanc, D. F. Kelton, J. Dubuc, and T. F. Duffield. 2012. Metabolic parameters in transition cows as indicators for early-lactation culling risk. J. Dairy Sci. 95:30573063. https://doi.org/10.3168/jds.2011-4937.

Roche, J. R., A. W. Bell, T. R. Overton, and J. J. Loor. 2013. Nutritional management of the transition cow in the 21st centuryA paradigm shift in thinking. Anim. Prod. Sci. 53:1000-1023. 10.1071AN12293.

Sakai, T., M. Hamakawa, and S. Kubo. 1996. Glucose and xylitol tolerance tests for ketotic and healthy dairy cows. J. Dairy Sci 79:372-377. https://doi.org/10.3168/jds.S0022-0302(96)76374-9.

Tao, S., and G. E. Dahl. 2013. Invited review: heat stress effects during late gestation on dry cows and their calves. J. Dairy Sci. 96:40794093. https://doi.org/10.3168/jds.2012-6278.

Urbaniak, G. C., and S. Plous. 2012. Research Randomizer (Version 4.0). Computer software. Accessed Jan. 25, 2016. http://www. randomizer.org/form.htm.

Wagner, S. A., and D. E. Schimek. 2010. Evaluation of the effect of bolus administration of $50 \%$ dextrose solution on measures of electrolyte and energy balance in postpartum dairy cows. Am. J. Vet. Res. 71:1074-1080. https://doi.org/10.2460/ajvr.71.9.1074.

Wohlt, J. E., J. L. Evans, and J. R. Trout. 1984. Blood constituents in lactating Holstein cows influenced by hematocrit, sampling site, and diet protein and calcium. J. Dairy Sci. 67:2236-2246. https:// doi.org/10.3168/jds.S0022-0302(84)81571-4. 